\title{
A Methodological Approach for Quantitative Assessment of the Effective Wastewater Management: Lebanon as a Case Study
}

\author{
Ali Karnib \\ Received: 9 July 2014 / Accepted: 27 August 2014 / Published online: 9 September 2014 \\ (C) Springer International Publishing Switzerland 2014
}

\begin{abstract}
The sustainable access to basic sanitation services is one of the targets of the Millennium Development Goals (MDGs) adopted by the United Nations in 2000. A monitoring and reporting program on progress made on access to improved sanitation services has been pursued by the global community using the universal indicator 'proportion of population using an improved sanitation facility'. However, monitoring and reporting progress using this indicator does not reflect the effective wastewater management and pollution control. This paper presents a methodological approach for quantitative assessment of the effective wastewater management based on non-additive aggregation methodology which accounts for the interactions among indicators. Firstly, a set of indicators are identified and calculation methods are presented. Secondly, the use of 2-order Choquet integral to aggregate indicators into an Effective Wastewater Management index (EWM) is proposed. At the practical level, results of evaluation of the EWM of the Wastewater Collection Systems in Lebanon are then presented and discussed. Finally, the conclusions and further developments are presented.
\end{abstract}

Keywords Effective wastewater management $\cdot$ Interacting indicators $\cdot$ Choquet integral

\section{Introduction}

Sustainable development indices are receiving increasing worldwide acceptance as they permit an easier monitoring and progress assessment towards particular targets. The Millennium Development Goal (MDG) No. 7 on ensuring environmental sustainability includes one target related to drinking water and sanitation, and challenges the world to halve, by 2015, the proportion of people without sustainable access to safe drinking water and basic sanitation (United Nations 2000). The sanitation part of this target is evaluated by the indicator 'proportion of population using an improved sanitation facility' (United Nations 2008).

The Joint Monitoring Programme (JMP) of the World Health Organization (WHO) and the United Nations Children's Fund (UNICEF) is the official United Nations mechanism for

\footnotetext{
A. Karnib $(\bowtie)$

Lebanese University, Hadath Campus, Baabda, Lebanon

e-mail: karnib.ali@gmail.com
} 
monitoring and reporting on the global status and the progress towards the water and sanitation targets (WHO 2000). An improved sanitation facility is defined by the JMP as one that hygienically separates human excreta from human contact (JMP 2014). Therefore, the proportion of the population using an improved sanitation facility is the percentage of the population who use any of the following types of facilities: connection to a public sewer; connection to a septic system; ventilated improved pit latrine; pour-flush latrines and simple pit latrines. It does not include public or shared latrines, open pit latrines and bucket latrines. Definitions and detailed description of these facilities could be obtained from JMP (2014). The MDG sanitation indicator is computed as the percentage of the population who use improved sanitation facilities to the total population. The estimates of proportion using improved sanitation facilities originate from data gathered through international household surveys and national censuses (WHO 2006).

The present MDG sanitation indicator addresses only access to basic sanitation which has been de facto restricted to access to toilets; accordingly, the use of toilets connected to piped sewer network is considered by JMP as improved sanitation facility. However, the collected wastewater returns back into rivers, lakes or groundwater and may cause damage to human health or to the environment. The degree of environmental risk associated with the disposal or reuse of wastewater could not be evaluated by the present universal sanitation indicator (UNESCWA 2013a; Kvarnström et al. 2011; Kuznyetsov 2007). In this regard, the global debates regarding the formulation of a Sustainable Development Goals (SDGs) during the preparation of a post-2015 development framework recognize the importance of delivering effective sanitation systems that could monitor and report on progress towards collection, treatment, reuse and disposal of wastewater (UN Water 2014). A review of the positions of most of the main actors that are participating to the deliberations on the post-2015 development agenda related to the water and sanitation sectors reveals a wide consensus that the SDGs need to incorporate three fundamentals, namely (UN-ESCWA 2013b): (a) integrated water resources management; (b) access to water and sanitation; and (c) effective wastewater management.

The inclusion of a wastewater management and pollution control target is, therefore, an essential component of any future water agenda. Such a target should stimulate national actions on progress towards protection of the human health and the environment.

This study proposes a methodological framework for quantifying and assessing the effective wastewater management for monitoring and reporting of the sustainable access to piped sewer system. In addition to the universal sanitation indicator (proportion of population connected to piped sewer network), four other indicators are considered and all are aggregated into an overall Effective Wastewater Management (EWM) index using Choquet integral aggregation methodology. The proposed approach is then applied to the wastewater collection systems in Lebanon. The proposed EWM takes values between 0 and $100 \%$ ranging from extremely ineffective wastewater management conditions, to totally effective conditions which are presently meeting the national wastewater management targets.

\section{Indicators Related to the Effective Wastewater Management}

Performance indicators can be defined as items of information collected at regular intervals to track the performance of a system and convey to policy makers important insights and directions (Fitz-Gibbon 1990). In addition to the universal sanitation indicator, various agencies and organizations worldwide have developed indicators to measure wastewater systems performance (Van Den Berg and Danilenko 2011; US EPA 2009; Alegre et al. 2006; Bagheri et al. 2006; Ashley and Hopkinson 2002; UN-ESCWA 2013a, b). The effective management 
should include three important aspects: wastewater treatment to protect the environment, wastewater and sludge reuse and energy production for sustainable operation, and resources optimization.

In line with the above three mentioned aspects, and based on the available data, a set of indicators are considered to evaluate an overall Effective Wastewater Management index (EWM). These indicators are:

- Proportion of population connected to piped sewer network (network coverage)

- Proportion of secondary treated wastewater

- Proportion of safe reuse of treated wastewater

- Proportion of safe reuse of treated sludge

- Proportion of biogas produced

The proportion of effluent that had undergone primary, secondary or tertiary treatment has been widely used as wastewater treatment indicator by different international environmental organizations (European Environment 2013; Van Den Berg and Danilenko 2011; US EPA 2009; UN-ESCWA 2013a, b). The wastewater treatment reflects the extent of environmental risk associated with the disposal of wastewater. The Urban Wastewater Treatment Directive adopted by the Council of the European Communities defines the concentration values of the relevant parameters that should be respected for the secondary treated wastewater and for the other levels of purification (Council of the European Communities 1991). Additionally, the safe reuse of treated wastewater and sludge can also reduce environmental risks by reducing wastewater and sludge discharge into the natural environment (Chowdhury and Al-Zahrani 2013; Council of the European Communities 1986, 1991). They can also increase agricultural production in countries where water resources are extremely limited such as the Arab region (UN-ESCWA 2013b). Moreover, biogas produced from wastewater sludge represents a valuable renewable energy source, and the resulting digested residues can be used as fertilizer for land application.

It is important to mention that each country is particular by its institutional, social, and economic conditions that influence its wastewater collection and treatment policies and strategies. The identification of indicators is influenced by the degree of development of the wastewater collection systems in the country and the availability of data related to these systems. Thus, the identified indicators and their methods of calculation could be approached in different ways according to the specific conditions of each country. At present, tertiary wastewater treatment plants in Lebanon are not applicable.

Table 1 provides measurable variables and methods of calculation of the considered indicators. The constituents of the treated effluent and treated sludge used in quantifying the indicators should be tested and complying with standards defined by the Council of the European Communities (1991). The safe reuse of treated wastewater and sludge should meet the necessary WHO (1989) guidelines.

\section{Proposed Method of Evaluation of the Effective Wastewater Management Index}

The proposed EWM index aggregates a set of indicators measuring particular characteristics of a wastewater system. This aggregate index has several positive aspects: it allows summarizing the relationship among the concerned indicators; it facilitates communication to the concerned wastewater systems managers; it serves as a basis for monitoring and reporting; and it allows the comparison of effective wastewater management progress between different wastewater 
Table 1 Descriptions, measurable variables and methods of calculation of the selected indicators

\begin{tabular}{|c|c|c|}
\hline Indicator & Measurable Variables & Calculation \\
\hline $\begin{array}{l}\text { Proportion of population connected to } \\
\text { piped sewer network ( } P C P)(\text { JMP 2014) }\end{array}$ & $\begin{array}{l}C P=\text { Population connected to piped sewer } \\
\text { network (No.) } T P=\text { Total population } \\
\text { (No.) }\end{array}$ & $P C P=\frac{C P}{T P} \times 100$ \\
\hline $\begin{array}{l}\text { Proportion of population connected to } \\
\text { secondary treatment (PCST) (European } \\
\text { Environment 2013; Van Den Berg and } \\
\text { Danilenko 2011; US EPA 2009; UN- } \\
\text { ESCWA 2013a; 2013b) }\end{array}$ & $\begin{array}{l}S T W=\text { Annual volume of collected domestic } \\
\text { wastewater which has undergone } \\
\text { secondary treatment }\left(\mathrm{m}^{3} / \text { year) } T C=\text { Total }\right. \\
\text { volume of collected domestic } \\
\text { wastewater }\left(\mathrm{m}^{3} / \text { year) }\right.\end{array}$ & $P C S T=\frac{S T W}{T C} \times 100$ \\
\hline $\begin{array}{l}\text { Proportion of safe reuse of treated } \\
\text { wastewater }(R T W)(\mathrm{UN}-\mathrm{ESCWA} \\
\text { 2013a, b) }\end{array}$ & $\begin{array}{l}S T W R=\text { Annual volume of secondary } \\
\text { treated domestic wastewater safely } \\
\left.\text { reused ( } \mathrm{m}^{3} / \text { year }\right) S T W=\text { Annual volume } \\
\text { of collected domestic wastewater which } \\
\text { has undergone secondary treatment } \\
\left(\mathrm{m}^{3} / \text { year }\right)\end{array}$ & $R T W=\frac{S T W R}{S T W} \times 100$ \\
\hline $\begin{array}{l}\text { Proportion of safe reuse of treated sludge } \\
\quad(R T S) \text { (set by author) }\end{array}$ & $\begin{array}{l}Q T S R=\text { Annual quantity of treated sludge } \\
\text { safely used in agriculture (in tons of dry } \\
\text { solids per year) (tDS/year) } T Q S=\text { Total } \\
\text { annual quantity of produced sludge } \\
\text { resulting from the primary and } \\
\text { secondary wastewater treatment } \\
\text { processes (tDS/year) }\end{array}$ & $R T S=\frac{Q T S R}{T Q S} \times 100$ \\
\hline $\begin{array}{l}\text { Proportion of biogas produced }(B P) \text { (set by } \\
\text { author) }\end{array}$ & $\begin{array}{l}Q B=\text { Annual quantity of biogas produced } \\
\text { ( } \mathrm{m}^{3} / \text { year) } T Q B=\text { Potential annual biogas } \\
\text { production from quantity of produced } \\
\text { sludge (resulting from the actual primary } \\
\text { and secondary wastewater treatment } \\
\text { processes) }\left(\mathrm{m}^{3} / \text { year) }\right.\end{array}$ & $B P=\frac{Q B}{T Q B} \times 100$ \\
\hline
\end{tabular}

systems and across different years. Various international development institutions and research groups have sought to define aggregate indices for the purpose of monitoring and reporting sustainable development and human wellbeing (Singh and Gupta 2009; Sadiq 2010; Hak et al. 2012; Mori and Christodoulou 2012; Bossel 1999). A review of major sustainable development indices could be found in Singh and Gupta (2009) and Mori and Christodoulou (2012).

The aggregation of sustainable development indices consists of two steps: in the first step, the considered indicators are normalized in a common measurement scale using a utility function; the second step is the application of an aggregation operator. The proposed indicators in this study are normalised by their formation and take values between 0 and $100 \%$ ranging from very low to very high performances.

The most common way to aggregate multiple indicators for the purpose of monitoring and reporting sustainable development is to use the weighted arithmetic average, where each weight is given by an expert to represent the importance of a particular indicator (Singh and Gupta 2009; Sadiq 2010; Hak et al. 2012; Mori and Christodoulou 2012; Bossel 1999). Simplicity and ease of use are the main advantages of this commonly used aggregation operator. However, the weighted average operators are suitable only if all the indicators are independent of each other, i.e., the measures of the indicators are additive. For measures that are non-additive, i.e., if there are synergy or redundancy among the indicators, information that is complementary or redundant is not properly accounted for by using the weighted average operators, which may lead to a bias in the overall assessment of the aggregated index. 
The five indicators considered in this study are not independent of each other. For example, the collected volume of wastewater is directly linked to the proportion of population connected to piped sewer network (network coverage). Moreover, wastewater reuse and sludge reuse are strongly correlated to wastewater treatment, and these are all related to the environmental protection risks.

In order to account for all mentioned correlations (interactions) among the individual indicators, any aggregation approach that is additive in nature, such as weighted average operators, cannot be selected. Instead, the use of discrete 2-order Choquet integral to account for correlation among the indicators is proposed. The discrete Choquet integral has been proposed by many authors as an aggregation tool of non-additive measures and as an adequate substitute to the weighted arithmetic mean to aggregate interacting indicators (Marichal 2002; Grabisch et al. 2003; Grabisch and Lebreusche 2010; Bebcakova et al. 2011). In this section, the Choquet integral aggregation model will be defined, and we will discuss the simplified 2order Choquet integral and demonstrate its application to evaluate the effective wastewater management index.

In the Choquet integral model, where indicators can be dependent, a fuzzy measure is used to define a weight on each combination of indicators, thus, making it possible to model the existing interaction among indicators. A finite universal set of indicators $N=\{1, \ldots, n\}$ will be considered, where $n$ is the cardinality of the set, i.e., $n=|N|$. A fuzzy measure $\mu$ on $N$ is defined as a monotone set function $\mu: 2^{N} \rightarrow[0,1]$ to indicate the importance of an indicator or a subset of indicators (also referred to as a coalition). The set function satisfies:

a- $\mu(\varnothing)=0$ (where $\varnothing$ represents an empty set), $\mu(N)=1$, and

b- for any subsets $S$ and $T, S \subseteq T \Rightarrow \mu(S) \leq \mu(T)$ (monotonicity).

The monotonicity property states that having more elements in a coalition does not reduce the importance of a coalition.

Consider the case of two indicators $i, j \in N$. If $\mu(i, j)=\mu(i)+\mu(j)$, the two indicators contain independent information; if $\mu(i, j)<\mu(i)+\mu(j)$, the two indicators are substitutive, i.e., simply adding the scores of both indicators leads to the inclusion of redundant information; if $\mu(i$, $j)>\mu(i)+\mu(j)$, the two indicators are complementary, i.e., having both indicators enhances the overall information content of the fuzzy measure $\mu$.

If $\left(x_{1}, x_{2}, \ldots, x_{n}\right)$ are the values of the normalized indicators, the Choquet integral of $\left(x_{1}, x_{2}\right.$, $\left.\ldots, x_{n}\right) \in \mathfrak{R}^{n}$ is defined as follows:

$$
C_{\mu}\left(x_{1}, x_{2}, \ldots, x_{n}\right)=\sum_{i=1}^{n} x_{(i)}\left[\mu\left(A_{(i)}\right)-\mu\left(A_{(i+1)}\right)\right]
$$

where $x_{(i)}$ is the normalised value of indicator $i$, and $x$ is permutated on $N$ such that $x_{(1)} \leq$ $x_{(2)} \leq \ldots \leq x_{(n)}, \mathrm{A}_{(i)}=\{(i), \ldots,(n)\}$, and $\mathrm{A}_{(n+1)}=\varnothing$. We, thus, observe that the weights related to the indicators when using the weighted arithmetic average operator have been substituted by the weights $\mu\left(i_{1}, \ldots, i_{k}\right)$ related to all the combinations of indicators, thus making possible to express dependence between some indicators. For demonstration purposes of the calculation of the Choquet integral, the reader could refer to Marichal (2002) and Grabisch et al. (2003, 2010).

Over a problem involving $n$ indicators, specification of the general Choquet integral requires $2^{n}$ coefficients in $[0,1]$ in order to define the fuzzy measure $\mu$ on every subset. It is very difficult to an expert to give such an amount of information. To handle this problem, Grabisch (1997) proposed to use the concept of $k$-order fuzzy measure Choquet integral which 
considers only the interactions of indicator sets with $k$ or fewer indicators. Practical applications indicate that the 2-order case is the most motivating, since it considers interactions between pairs of indicators and at the same time it is not very complicated (Marichal and Roubens 2000; Berry et al. 2007; Zhang 2012). In this particular case, only $\frac{n(n+1)}{2}$ coefficients are required to define the fuzzy measures; the Choquet integral becomes $(\wedge$ denotes the minimum operation):

$$
C_{\mu}\left(x_{1}, x_{2}, \ldots, x_{n}\right)=\sum_{i N} a(i) x_{i}+\sum_{\{i, j\} \subseteq N} a(i j)\left(x_{i} \wedge x_{j}\right)
$$

where the weights $a(i), i \in N$, and $a(i j),\{i, j\} \subseteq N$, fully specify the Choquet integral model. Details of the derivation are given in (Marichal and Roubens 2000) and Grabisch (1997). The coefficient $a(i) \in[0,1]$ describes the relative importance of indicator $i$ (a greater value denotes greater relative importance); whereas $a(i j) \in[-1,1]$ describes the interaction between indicators $i$ and $j$, i.e., if they contain information that is independent, redundant, or complementary; $a(i j)>0$ indicates that $i$ and $j$ are complementary indicators; while $a(i j)<0$ indicates that they are substitutive; finally $a(i j)=0$ indicates that there is no correlation between them.

The following boundary and monotonicity conditions must be ensured (Marichal and Roubens 2000):

$$
\begin{aligned}
& a(\varnothing)=0, \\
& \sum_{i N} a(i)+\sum_{\{i, j\} \subseteq N} a(i j)=1, \\
& a(i) \geq 0, \forall i \in N, \\
& a(i)+\sum_{j \in T} a(i j) \geq 0, \forall i \in N, \forall T \subseteq N \backslash i .
\end{aligned}
$$

Finally, the relation between the real weights of indicators $I(i)$ (known also as Shapley index), the apparent weights $a(i)$ and the interaction weights $a(i j)$ could be obtained and written by Grabisch and Lebreusche (2010) and Marichal and Roubens (2000):

$$
I(i)=a(i)+\frac{1}{2} \sum_{j \backslash \backslash i} a(i j), i \in N,
$$

where: $I(i) \in[0,1]$ for all $i \in N$ and

$$
\sum_{i \in N} I(i)=1
$$

The weights of interacting indicators should be identified based on experts' elicitations. We propose to address the problem of identification of weights through the following steps:

Step 1 Define the real weights of indicators $I(i) \in[0,1]$ for all $i \in N$, ranging from low importance to high importance respectively with $\sum I(i)=1$.

Step 2 Define the interaction coefficients $a(i j)$ for all $\{i, j\} \subseteq N$.

Step 3 Using equation (3), calculate the apparent weights of indicators $a(i)$ for all $i \in N$. 
Table 2 Experts' insights and the related weights

Experts' insights

The weights agreed upon by experts

PCST is the most important indicator due to its direct high impacts on environmental protection, $I(P C S T)>I(P C P)>$ $I(R T W)>I(R T S)=I(B P)$

The digested residues of sludge used in energy production are generally reused as fertilizers in agriculture, therefore, there is some overlap between RTS and BP.

There are complementary information between $P C P$ and $P C S T$, and between PCST and the three indicators: $R T W, R T S$ and $B P$. The positive interaction of (PCP and PCST), (PCST and $R T W),(P C S T$ and RTS) and (PCST and BP) are rather important for effective wastewater management and must be favoured.

There is independent information between $P C P$ and the three indicators: $R T W, R T S$ and $B P$, and also between $R T W$ and the two indicators: RTS and $B P$.

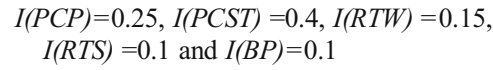

$a(R T S B P)=-0.05(<0$ indicates redundancy between $R T S$ and $B P$ )

$a(P C P$ PCST $)=a(P C S T R T W)=0.18$ and $a$ $(P C S T$ RTS $)=a($ PCST BP $)=0.12$

$a(P C P R T W)=a(P C P R T S)=a(P C P B P)=$ $a(R T W R T S)=a(R T W B P)=0$

For the particularity of our case study, the weights of interacting indicators are identified based on Lebanese experts' elicitations. Table 2 presents the insights and values of weights that resulted from the discussion with the experts.

Using equation (3), the apparent weights of indicators $a(i)$ for all $i \in N$ are calculated. Results of indicators weights are shown in Tables 3 and 4.

\section{Study Area}

At present, the population of Lebanon accounts about 4.28 million and produces about 233 million cubic meters of domestic wastewater annually (MEW 2012a, b). The responsibilities of water supply and wastewater collecting and treatment systems in Lebanon are delegated to the following four Regional Water Authorities (RWAs): Beirut and Mount Lebanon (BML); North Lebanon; South Lebanon; and Bekaa. Table 5 presents the population served by RAWs and the data of the measurable variables necessary to evaluate the proposed indicators for years 2000, 2005, 2010 and 2014. These data are obtained from the available records at the Regional Water Authorities (RAWs) and the Ministry of Energy and Water (MEW) in Lebanon (MEW 2012a, b).

\section{Applications and Analysis of Results}

The evaluation of the EWMs of the wastewater collecting systems in the four RWAs will be presented through the various steps of the proposed methodology.

Table 3 Weights $a$ (i) for the different indicators

\begin{tabular}{|c|c|c|c|c|c|}
\hline & PCP & PCST & RTW & RTS & $\mathrm{BP}$ \\
\hline$a(i)$ & 0.16 & 0.10 & 0.06 & 0.065 & 0.065 \\
\hline
\end{tabular}


Table 4 Interaction indices $a$ (ij) between the different indicators

\begin{tabular}{llllll}
\hline & & PCP & PCST & RTW & RTS \\
\hline$a(i j)$ & PCST & 0.18 & & & \\
& RTW & 0 & 0.18 & & \\
RTS & 0 & 0.12 & 0 & -0.05 \\
BP & 0 & 0.12 & 0 & \\
\hline
\end{tabular}

First, the values of the considered indicators are calculated based on data presented in Table 5. Table 6 presents the resulting values of indicators. The 2-order Choquet integral is thus calculated and the effective wastewater management indices for years 2000, 2005, 2010 and 2014 are evaluated. The results are presented in Table 7. Fig. 1 presents the EWM indices along with the concerning indicators for the four RWAs in Lebanon for years 2000, 2005, 2010 and 2014. The progresses gained of the EWM indices from 2000 to $2014\left(\mathrm{EWM}_{2014}(\%)\right.$ $\left.\mathrm{EWM}_{2000}(\%)\right)$ are shown in Fig. 2.

Over the past 14 years, significant progress was made in connecting population to wastewater collecting systems in all RWAs in Lebanon. The wastewater collection network coverage in BML water authority was $60 \%$ in 2000 and reached $84 \%$ in 2014. This high proportion of progress is a pointer of the high financial investment in the construction of piped sewer networks in Lebanon since 2000. However, by evaluating the effectiveness of wastewater management along with these achievements, the EWM indices show a very low performance with a score range between 19.6\% (BML) and 27.6\% (North Lebanon) in 2014 (Table 7).

Table 5 Data of the measurable variables and the resulted values of indicators

\begin{tabular}{|c|c|c|c|c|c|c|c|c|c|c|}
\hline $\begin{array}{l}\text { Water } \\
\text { Authority }\end{array}$ & Year & $\begin{array}{l}T P \\
(\text { No. }) \\
\left(\times 10^{3}\right)\end{array}$ & $\begin{array}{l}C P \\
(\text { No. }) \\
\left(\times 10^{3}\right)\end{array}$ & $\begin{array}{l}\text { TC } \\
\left(\mathrm{m}^{3} /\right. \\
\text { year }) \\
\left(\times 10^{3}\right)\end{array}$ & $\begin{array}{l}S T W \\
\left(\mathrm{~m}^{3} / \text { year }\right) \\
\left(10 \times^{3}\right)\end{array}$ & $\begin{array}{l}\begin{array}{l}S T W R \\
\left(\mathrm{~m}^{3} /\right.\end{array} \\
\text { year) } \\
\left(10 \times^{3}\right)\end{array}$ & $\begin{array}{l}\text { QTSR } \\
\text { (tDS/ } \\
\text { year) }\end{array}$ & $\begin{array}{l}\text { TQS } \\
\text { (tDS/ } \\
\text { year) }\end{array}$ & $\begin{array}{l}\text { QB } \\
\left(\mathrm{m}^{3} / \text { year }\right) \\
\left(10 \times^{3}\right)\end{array}$ & $\begin{array}{l}\text { TQB } \\
\left(\mathrm{m}^{3} / \text { year }\right) \\
\left(10 \times^{3}\right)\end{array}$ \\
\hline \multirow[t]{4}{*}{ BML } & 2000 & 1700 & 1020 & 31646 & 380 & 50 & 25 & 367 & 0 & 126 \\
\hline & 2005 & 1825 & 1285 & 47841 & 710 & 250 & 39 & 572 & 0 & 197 \\
\hline & 2010 & 1960 & 1465 & 68177 & 2050 & 1000 & 92 & 1322 & 0 & 455 \\
\hline & 2014 & 2104 & 1770 & 93354 & 2150 & 1500 & 125 & 1320 & 0 & 454 \\
\hline \multirow{4}{*}{$\begin{array}{l}\text { North } \\
\text { Lebanon }\end{array}$} & 2000 & 703 & 232 & 6838 & 450 & 36 & 34 & 458 & 0 & 158 \\
\hline & 2005 & 755 & 281 & 8718 & 1018 & 120 & 76 & 984 & 0 & 339 \\
\hline & 2010 & 810 & 348 & 15115 & 2105 & 496 & 226 & 1454 & 3 & 500 \\
\hline & 2014 & 870 & 423 & 26247 & 6924 & 2310 & 1155 & 3348 & 21 & 1152 \\
\hline \multirow{4}{*}{$\begin{array}{l}\text { South } \\
\text { Lebanon }\end{array}$} & 2000 & 608 & 182 & 5093 & 40 & 5 & 5 & 43 & 0 & 15 \\
\hline & 2005 & 653 & 250 & 7756 & 1200 & 200 & 152 & 1160 & 0 & 399 \\
\hline & 2010 & 701 & 290 & 11696 & 2130 & 500 & 252 & 1584 & 5 & 545 \\
\hline & 2014 & 753 & 330 & 18429 & 3950 & 1000 & 563 & 2122 & 8 & 730 \\
\hline \multirow[t]{4}{*}{ Bekaa } & 2000 & 451 & 94 & 2566 & 110 & 37 & 34 & 121 & 0 & 42 \\
\hline & 2005 & 484 & 134 & 3949 & 586 & 236 & 226 & 596 & 0 & 205 \\
\hline & 2010 & 520 & 173 & 5367 & 964 & 423 & 412 & 932 & 4 & 321 \\
\hline & 2014 & 558 & 201 & 9354 & 1954 & 998 & 596 & 1260 & 5 & 433 \\
\hline
\end{tabular}

(MEW 2012a, b) and data compiled by the author 
Table 6 Resulting values of indicators

\begin{tabular}{|c|c|c|c|c|c|c|}
\hline Water Authority & Year & PCP (\%) & PCST $(\%)$ & RTW (\%) & RTS (\%) & $\mathrm{BP}(\%)$ \\
\hline \multirow[t]{4}{*}{ BML } & 2000 & 60.0 & 1.2 & 13.2 & 6.8 & 0.0 \\
\hline & 2005 & 70.4 & 1.5 & 35.2 & 6.8 & 0.0 \\
\hline & 2010 & 74.7 & 3.0 & 48.8 & 7.0 & 0.0 \\
\hline & 2014 & 84.1 & 2.3 & 69.8 & 9.5 & 0.0 \\
\hline \multirow[t]{4}{*}{ North Lebanon } & 2000 & 33.0 & 6.6 & 8.0 & 7.4 & 0.0 \\
\hline & 2005 & 37.2 & 11.7 & 11.8 & 7.7 & 0.0 \\
\hline & 2010 & 42.9 & 13.9 & 23.6 & 15.5 & 0.6 \\
\hline & 2014 & 48.6 & 26.4 & 33.4 & 34.5 & 1.8 \\
\hline \multirow[t]{4}{*}{ South Lebanon } & 2000 & 30.0 & 0.8 & 12.5 & 11.6 & 0.0 \\
\hline & 2005 & 38.3 & 15.5 & 16.7 & 13.1 & 0.0 \\
\hline & 2010 & 41.4 & 18.2 & 23.5 & 15.9 & 0.9 \\
\hline & 2014 & 43.8 & 21.4 & 25.3 & 26.5 & 1.1 \\
\hline \multirow[t]{4}{*}{ Bekaa } & 2000 & 20.8 & 4.3 & 33.6 & 28.1 & 0.0 \\
\hline & 2005 & 27.7 & 14.8 & 40.3 & 37.9 & 0.0 \\
\hline & 2010 & 33.3 & 18.0 & 43.9 & 44.2 & 1.2 \\
\hline & 2014 & 36.0 & 20.9 & 51.1 & 47.3 & 1.2 \\
\hline
\end{tabular}

These low EWM scores indicate that the collected wastewater in Lebanon are ineffectively managed and severely negatively affecting the environment.

As illustrated in Fig. 1, the low EWM scores are due to the low performance of the considered indicators. Moreover, as can be seen in Fig. 2, the progress gained towards EWM by North Lebanon water authority since 2000 is the highest among the RWAs with a value of $17.5 \%$.

The above mentioned results confirm the necessity to put the wastewater collecting systems in Lebanon on a sustainable footing and protecting the environment by developing wastewater infrastructure to increase treatment capacities and ensuring reuse where possible. In addition, the increased coverage of collection networks should be conceived and executed along with the adequate treatment capacity and reuse options.

With the purpose to compare the calculated EWM based on the Choquet integral and when using the weighted average approach, the EWM scores for the year 2014 are calculated by the weighted average operator (WAO) and results are presented in Table 8. The EWM score of BML in 2014 calculated by WAO is the highest among the RWAs. However, despite its high sewer network connection rate $(P C P$ indicator), BML has a very low proportion of population connected to secondary treatment (PCST indicator). This is rather critical, since it severely

Table 7 Results of the proposed Effective Wastewater Management Index (EWM) (\%)

\begin{tabular}{lrrrrr}
\hline Water Authority & \multicolumn{2}{l}{ Year } & & Progress 2000-2014 \\
\cline { 2 - 5 } & 2000 & 2005 & 2010 & 2014 & 8.1 \\
\hline BML & 11.5 & 14.7 & 17.1 & 19.6 & 17.5 \\
North Lebanon & 10.1 & 13.5 & 17.5 & 27.6 & 16.0 \\
South Lebanon & 6.8 & 16.7 & 19.5 & 22.8 & 14.5 \\
Bekaa & 9.7 & 17.9 & 21.4 & 24.2 & \\
\hline
\end{tabular}



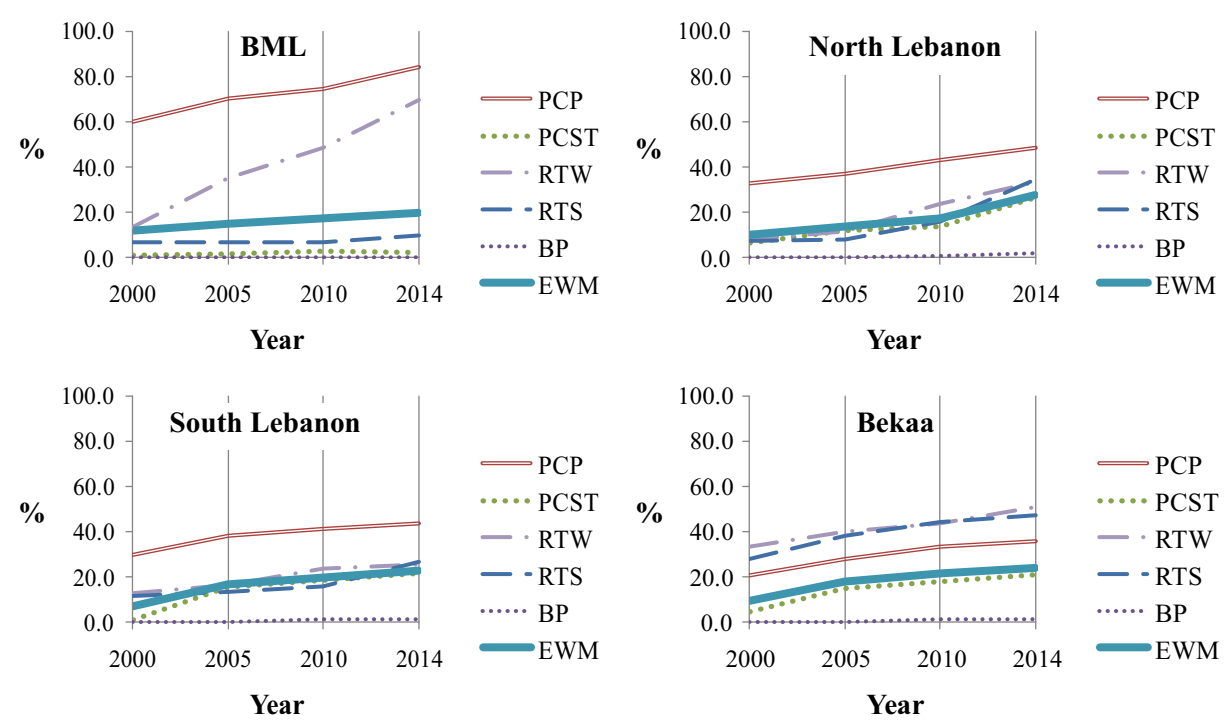

Fig. 1 The EWM indices along with the concerning indicators for the four RWAs

negatively impacts the environment and represents a highly ineffective wastewater management condition. Furthermore, North Lebanon is not as good as BML for PCP, but indeed, it has balanced scores on all indicators. The wastewater management experts consider that North

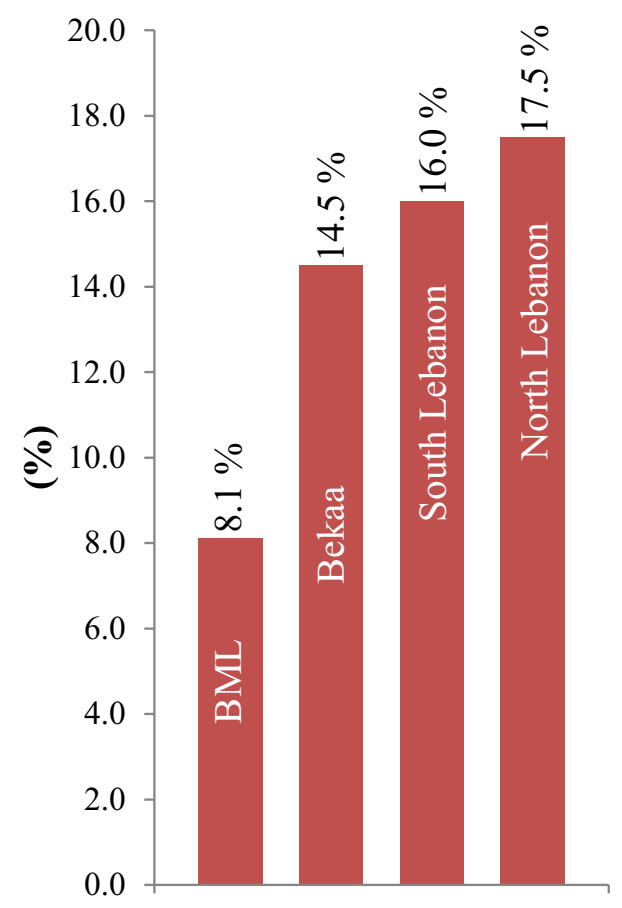

Fig. 2 Progresses gained of the EWM indices since $2000(\%)$ 
Table 8 Results of EWM (\%) for 2014 calculated by using the weighted average operator

Water Authority

\begin{tabular}{llll}
\hline BML & North Lebanon & South Lebanon & Bekaa \\
33.4 & 31.3 & 26.1 & 29.9 \\
\hline
\end{tabular}

Lebanon should get a better EWM score compared to BML. Therefore, the additive model is not appropriate to calculate EWM since it cannot consider the complementary and the redundancy among the indicators. In fact, wastewater management experts consider that both indicators $P C P$ and PCST have to be satisfactory in order to get a satisfactory EWM, the satisfaction of only one indicator being inadequate. The same condition applies to (PCST and $R T W),(P C S T$ and RTS) and (PCST and BP). In line with this, the scores of the EWM calculated by Choquet integral presented in the study are consistent with experts' judgments.

Lastly, in order to analyze the robustness of the EWM ranks, a sensitivity analysis has been performed for the EWM scores in 2014 using 25 random sets of weights varying within the interval of $\pm 20 \%$ of the original set values expressed by the experts. The sensitivity analysis has shown a complete agreement in ranking along with the original EWM scores for the four RWAs. Nevertheless, the use of the proposed approach to evaluate and monitor the EWM across countries necessitates performing additional rigorous robustness/sensitivity analyses to analyze the distributions of the EWM scores and ranks compared to reference EWM results.

\section{Conclusions}

This study proposes a methodological framework for quantifying the effectiveness of wastewater management. Wastewater treatment, reuse and biogas production indicators were proposed to provide an understanding of the effective management of the collected wastewater. Typically, indicators used in the effective management assessment are not independent. To appropriately consider inter-linkages and synergies across indicators, the 2-order Choquet integral model was proposed to aggregate the indicators into an overall Effective Wastewater Management Index. The proposed approach is then applied to the wastewater collecting systems in Lebanon.

The established Effective Wastewater Management Index aims to improve monitoring and reporting towards reliable wastewater collecting systems. This research will help to strengthen the capacity of water authorities in monitoring the progress towards sustainable sanitation systems. The proposed approach could also be used to evaluate and monitor the progress of EWM across groups of countries; in this respect, it is necessary to perform sufficient coordination between countries to identify optimal common weights. It is expected that the use of the proposed index will contribute to the enrichment of the regional and global debates regarding the formulation of a Sustainable Development Goals during the preparation of a post-2015 development framework. Such goals should monitor and stimulate national and regional actions on progress towards collection, treatment, reuse and disposal of wastewater.

The following two aspects of the developed approach merit further comments:

(1) At this stage, the considered indicators focus on piped sewer networks; the extension of this approach will be to consider additional wastewater management indicators including those applied to all improved sanitation facility options (such as on-site individual sanitation systems in rural areas). 
(2) Expand the number of experts involved into the elicitation of the weights process to include specialists in various wastewater related fields, such as environment, agriculture and energy in order to ensure that as many possible as different perspectives will be taken into consideration.

These two aspects are still under development at our university to promote access to sustainable sanitation facilities in developing countries.

\section{References}

Alegre H, Baptista JM, Cabrera E Jr, Cubillo F, Duarte P, Hirner W, Merkel W, Parena R (2006) Performance Indicators for Water Supply Services. IWA Publishing, London

Ashley R, Hopkinson P (2002) Sewer systems and performance indicators: into the 21st Century. Urban Water J 4(2):123-135

Bagheri A, Asgary A, Levy J, Rafeian M (2006) A performance index for assessing urban water systems: a fuzzy inference approach. J-Am Water Works Assoc 98(11):84-92

Bebcakova I, Holecek P, Talasova J (2011) On the application of the fuzzified Choquet Integral to multiple criteria evaluation. Acta Polytech Hung 8(3):65-78

Berry PM, Gervasio M, Peintner B, Yorke-Smith N (2007) A preference model for over-constrained meeting requests, in Proceedings of the AAAI 2007 Workshop on Preference Handling for Artificial Intelligence, pp $7-14$

Bossel H (1999) Indicators for Sustainable Development: Theory, Method, Applications, International Institute for Sustainable Development (IISD).

Chowdhury S, Al-Zahrani M (2013) Fuzzy synthetic evaluation of treated wastewater reuse for agriculture. Environ Dev Sustain. doi:10.1007/s10668-013-9491-8

Council of the European Communities (1986) Directive on the protection of the environment, and in particular of the soil, when sewage sludge is used in agriculture, Official Journal of the European Communities, (86/278/ EEC).

Council of the European Communities (1991) Urban Waste Water Directive, Official Journal of the European Communities (91/271/EEC).

European Environment Agency (2013) Urban waste water treatment (CSI 024) - Assessment published Jan 2013. European Environment Agency Web. http://www.eea.europa.eu/data-and-maps/indicators/urban-wastewater-treatment/urban-waste-water-treatment-assessment-3. Accessed 25 March 2014.

Fitz-Gibbon CT (1990) Performance indicators, BERA Dialogues (2), ISBN 978-1-85359-092-4.

Grabisch M (1997) k-order additive discrete fuzzy measures and their representation. Fuzzy Sets Syst 92:167189

Grabisch M, Lebreusche C (2010) A decade of application of the Choquet and Sugeno integrals in multi-criteria decision aid. Ann Oper Res 175(1):247-290

Grabisch M, Lebreusche C, Vasnick JC (2003) On the extension of pseudo-boolean functions for the aggregation of interaction criteria. Eur J Oper Res 148(1):28-47

Hak T et al (2012) Review report on Beyond GDP indicators: categorisation, intensions and impacts. BRAINPOOL deliverable $1: 1$

JMP (2014) JMP Web. http://www.wssinfo.org/definitions-methods/watsan-categories/. Accessed 25 March 2014.

Kuznyetsov V (2007) Millennium development goals - problems of turning commitment into reality, Stockholm International Water Institute: Abstract Volume World Water Week, Stockholm, August 12-18, 2007

Kvarnström E, McConville J, Bracken P, Johansson M, Fogde M (2011) The sanitation ladder - a need for a revamp? J Water, Sanitation and Hygiene for Development 1:3-12. doi:10.2166/washdev.2011.014

Marichal JL (2002) Aggregation of interacting criteria by means of the discrete Choquet integral. Studies in Fuzziness and Soft Computing 97:224-244

Marichal JL, Roubens M (2000) Determination of weights of interacting criteria from a reference set. European J of Operational Research 124(3):641-650

MEW (2012a) National Water Sector Strategy, Ministry of Energy and Water, (Resolution No. 2, Date 09/03/2012)

MEW (2012b) National Strategy for the Wastewater Sector, Ministry of Energy and Water, (Resolution No. 35, Date $17 / 10 / 2012)$ 
Mori K, Christodoulou A (2012) Review of sustainability indices and indicators: Towards a new City Sustainability Index (CSI). Environ Impact Assess Rev 32(1):94-106

Sadiq R (2010) Integrating indicators for performance assessment of small water utilities using ordered weighted averaging (OWA) operators. Expert Systems with Applications 37:4881-4891

Singh M, Gupta D (2009) An overview of sustainability assessment methodologies. Ecol Indic 9:189-212

U.S. Environmental Protection Agency (US EPA) (2009) State of the Great Lakes, EPA 950 K 09 001, Washington, DC

UN-ESCWA (2013a) Report: Tenth session of the committee on water resources - Beirut, 20-22 March 2013, UN-ESCWA, Beirut, Lebanon, E/ESCWA/SDPD/2013/IG.1/8/Report.

UN-ESCWA (2013b) Water Development Report 5 - Issues in Sustainable Water Resources Management and Water Services, UN-ESCWA, Beirut, Lebanon, E/ESCWA/SDPD/2013/4.

United Nations (2000) United Nations Millennium Declaration, General Assembly, United Nations, New York, $\mathrm{A} / \mathrm{RES} / 55 / 2$.

United Nations (2008) Report of the Secretary-General on the Indicators for Monitoring the Millennium Development Goals, Economic and Social Council, United Nations, New York, E/CN.3/2008/29.

Van Den Berg C, Danilenko A (2011) The IBNET water supply and sanitation performance Blue Book, The International Benchmarking Network for Water and Sanitation Utilities Data book. Water and Sanitation Program World Bank, Washington

UN Water (2014) A Post-2015. Global Goal for Water: Synthesis of key findings and recommendations from UN-Water, UN-Water, Geneva, Switzerland.

WHO (1989) Guidelines for the safe use of wastewater and excerta in agriculture and aquaculture. WHO Press, Geneva

WHO \& UNICEF (2000) Global Water Supply and Sanitation Assessment 2000 Report, WHO Press, Geneva, Switzerland

WHO \& UNICEF (2006) Core questions on drinking-water and sanitation for household surveys, WHO Press, Geneva, Switzerland

Zhang Y (2012) Using the Choquet integral for screening geological CO2 storage sites. Greenhouse Gases: Science and Technology 1(2):175-179 